\title{
Study on the Installation Technology of the Pile Head Treatment Device for Minor Diameter Rigid Pile Vertical Static Load Test
}

\author{
Xin-Quan WANG ${ }^{1, a,{ }^{*}, \text { Yun-Liang CUI }}{ }^{1, b}$, Shi-Min ZHANG $^{1, c}$, Guang-Tong LI ${ }^{2, d}$, \\ Jing-Li HAN ${ }^{2, d}$
}

${ }^{1}$ Department of Civil Engineering, Zhejiang University City College, Hangzhou 310015, China

${ }^{2}$ Dezhou Highway Engineering Corporation, Dezhou 253000, China

awangxq@zucc.edu.cn, bcuiy@zucc.edu.cn, zhangsm@zucc.edu.cn, ddzglgchchbgs@163.com

${ }^{*}$ Corresponding author

Keywords: Minor Diameter Rigid Pile, Static Load Test, Pile Head Treatment, Special-shaped Pile.

\begin{abstract}
During static load test, the pile body is likely to have the problem of eccentric compression. Engineering practice suggests that the key of static load test lies in the avoidance of pile eccentric compression, the precise control of pile driving pressure, and accurate measurement of vertical deformation of the pile by dial indicator, especially for minor diameter plain concrete piles. Therefore, this paper made an improvement in the traditional static load test device, developed an installation technology of the pile head treatment device for vertical static load test of minor diameter rigid embankment pile regarding the special-shaped pile, and introduced the technology in terms of technical principles, scope of application, technical features, construction technique and operating points.
\end{abstract}

\section{Introduction}

Static load test is the most direct, basic and reliable method among the various methods for determining the ultimate bearing capacity of a single pile, in which parameter such as load transfer, pile side resistance, pile tip resistance, pile body axial force, load-subsidence relation can be obtained by embedding test components. Zhang Hao ${ }^{[1]}$ conducted static load test of the precast piles used in a certain project, and applied the finite element method to make numerical analysis of the single precast pile composite foundation, inversely calculated the soil mass parameters, and the calculation results turned out to be close to the empirical value. Hong Changdi ${ }^{[2]}$ compared the advantages and disadvantages of three methods that consider the frictional resistance of the excavation section through the static load test in a site with a relatively deep excavation depth, and provided suggestions for improvement.

So far, there have also been some studies on the device of static load test. Liu Ronggui ${ }^{[3]}$ et al. studied the new straight cylinder + inner cone + straight cylinder anchoring solution, compared the contact stress and friction stress of the cylinder wall of anchorage device before and after the optimization by finite element modeling, and the analysis result was well matched. Wu Yuhua ${ }^{[4]}$ introduced the common reaction devices used for foundation load plate test and foundation piles static load test and discussed the advantages and disadvantages of them. Wang Guoliang ${ }^{[5]}$ introduced the design of the reaction frame for static load test in Ningde Bridge beam manufacturing plant, as the self-balanced steel truss girder reaction frame was used as loading equipment for static load test there.

\section{Technical Principles and Scope of Application}

(1) Technical principles

The technical principles of the installation technology of the pile head treatment device for vertical static load test of minor diameter rigid embankment pile are as follows: weld a horizontal dead plate and a vertical guard plate together to form a pile head pressure-bearing hoop, for special-shaped piles consolidation diagonal bracing can be added for the pressure-bearing hoop and 
should be fixed on the pile head through bolt; secure the bearing plate on the horizontal dead plate via a flexible connection; install a jack in the jack fixing ring on the bearing plate, and set two levels symmetrically on each side of the jack; install a load sensor on the I-beam above the jack and connect it with a frequency meter; drive a reference pile and install a reference beam, install a dial indicator on the reference beam, insert the end of the measuring bar of dial indicator into the groove of the bearing plate, as shown in Fig.1. During the installation, the pile head pressure-bearing hoop, bearing plate, jack, load sensor and I-beam should be in the same the same axis, to avoid the pile eccentric compression.

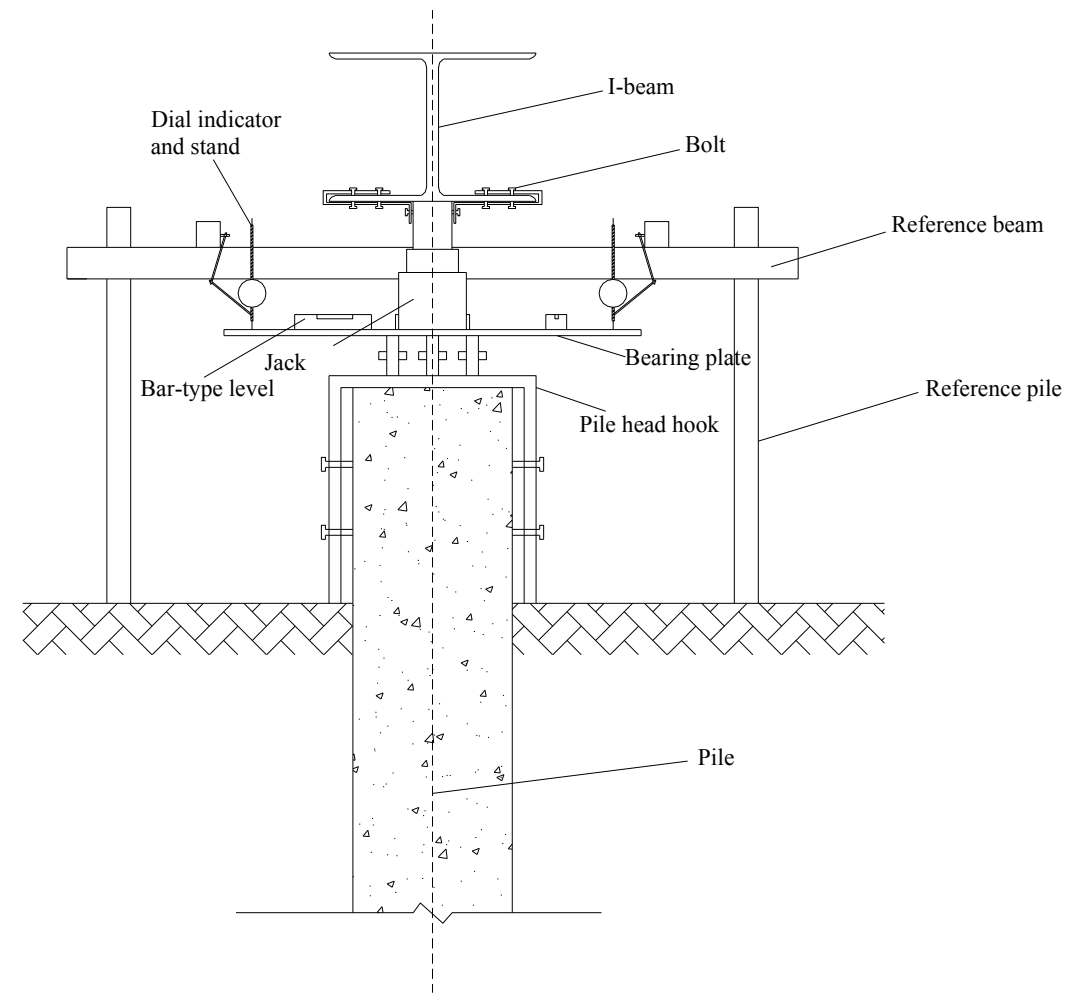

Fig.1 Pile Head Treatment Device for Circular Pile Vertical Static Load Test

(2) Scope of application

The installation technology of the pile head treatment device for vertical static load test of minor diameter rigid embankment pile is applicable for the static load test of common minor diameter circular pile, as well as the static load test of special-shaped pile.

\section{Technical Features}

The technology owns the following advantages:

(1) The pile head treatment device for vertical static load test of minor diameter rigid embankment pile in the technology uses the leveling foot screw and the levels on each side of the jack on the bearing plate to jointly control the test device to maintain level, which can effectively solve the problem of the difficult location of the center of minor diameter rigid pile which may lead to eccentric compression.

(2) The pile head treatment device for static load test in the technology uses load sensor and oil pressure gauge together to control the pile driving pressure, and perform gradation loading and unloading according to the requirements, able to precisely control the pile driving pressure.

(3) A dial indicator measuring bar is installed on the reference pile, and the pile head pressure-bearing hoop, bearing plate, jack, load sensor and I-beam are in the same the same axis, which enables the accurate measurement of the vertical deformation of minor diameter rigid embankment pile, and the avoidance of pile eccentric compression, thus guarantees the data accuracy of static load test. 


\section{Process and Operating Points}

(1) Materials

1) Bolt

The required bolts are M22 $\times 60$ high-strength hexagon fixing bolts at Grade 8.8 or above, with a nominal tensile strength not less than $800 \mathrm{~N} / \mathrm{mm}^{2}$ and a nominal yield strength not less than 640 $\mathrm{N} / \mathrm{mm}^{2}$

2) Steel plate

$12 \mathrm{~mm}$-thick hot-rolled steel plates are required for the horizontal dead plate, vertical guard plate and bearing plate.

3) I-beam

Model 20a I-beam is required, namely with $200 \mathrm{~mm}$ height, $100 \mathrm{~mm}$ leg length, $7 \mathrm{~mm}$ waist depth, $11.4 \mathrm{~mm}$ average leg thickness, and $35.5 \mathrm{~mm}^{2}$ cross-sectional area.

(2) Operating points

1) Preparation

The preparation works includes the removal of crush layer and weak concrete on the top of pile, the excavation of soil within a certain scope around the top of pile to make the pile head exposed and the rubdown of pile head, and the laying of fine sand on the top of pile.

2) Installation of pile head pressure-bearing hook

The horizontal dead plate and vertical guard plate are all $12 \mathrm{~mm}$-thick steel plates, fixed together by welding. The horizontal dead plate is fan-shaped, on which $0.05 \times 0.025$ rectangular bolt sliding groove is opened, and the center line of its long side coincides with the direction of radius. The pile head pressure-bearing hook is formed when the horizontal dead plate and the vertical guard plate are connected by welding. The diagonal brace uses circular steel tube or angle steel, with one end welded with the edge of horizontal dead plate with $45^{\circ}$ intersection angle, and the other end welded with the inverted arch curved surface vertical guard plate. There are totally 4 diagonal braces, distributed uniformly. Bolt holes are opened on the vertical guard plate, and there are totally 3 bolt holes which distribute in the shape of regular triangle, with an aperture of $25 \mathrm{~mm}$. Fixing gasket is additionally mounted for bolt hole, both the bolt holes and fixing gaskets have internal thread.

3) Installation of bearing plate

Square steel plate with dimensions of $0.9 \mathrm{~m} \times 0.9 \mathrm{~m} \times 12 \mathrm{~mm}$ is used as pile head bearing plate, on which 9 bolt sliding grooves with the size of $0.1 \mathrm{~m} \times 0.025 \mathrm{~m}$ are uniformly distributed, and the position of the sliding groove is consistent with that of the bolt sliding groove on the horizontal dead plate. The bearing plate and horizontal dead plate are secured with M22 $\times 60$ high-strength hexagon fixing bolts at Grade 8.8 or above.

4) Installation of jack

The jack is placed in the jack fixing ring of the bearing plate, and during the installation the sundries in the fixing ring should be cleared to avoid the inclination of the jack. The jack preloading should be performed before test, to ensure that each part of the device is closely contacted.

5) Installation of load sensor

Installation of the load sensor fixing device: connect the load sensor fixing device and I-beam by bolted connection, and adjust the fixing bolt with wrench, to ensure that the connection between the load sensor fixing device and I-beam is solid and the center lines of the two are in the same line.

6)Leveling of bearing plate

Adjust the leveling foot screw of the bearing plate repeatedly with a wrench, to make all the primary and auxiliary bubbles of the bar-type level in the center. During the test the leveling foot screw should be adjusted in time to guarantee the levelness of the bearing plate.

7) Heap loading

Perform heap loading on the heap loading reaction platform, as shown in Fig.2. The load should be heaped at one time, to keep the balance of the load, and ensure that the center of gravity of load go through the test pile center, meanwhile the total load should not less than 1.2 times of the 
scheduled maximum load.

\section{Summary}

We drew the following conclusions through the construction application and measured data of field static load test:

(1) The pile head treatment device for vertical static load test of minor diameter rigid embankment pile in the technology uses the leveling foot screw and the levels on each side of the jack on the bearing plate to jointly control the test device to maintain level, which can effectively solve the problem of the difficult location of the center of minor diameter rigid pile which may lead to eccentric compression.

(2) While applying the technology, dial indicator measuring bar is installed on the reference pile, and the pile head pressure-bearing hoop, bearing plate, jack, load sensor and I-beam are in the same the same axis, which enables the accurate measurement of the vertical deformation of minor diameter rigid embankment pile, and the avoidance of pile eccentric compression, thus guarantees the data accuracy of static load test.

(3) The technology provides the pile head hoop devices and the corresponding installation methods respectively for the circular pile and the special-shaped pile, which effectively solves the common problems that minor diameter piles, especially special-shaped piles, would encounter in static load test.

\section{Acknowledgement}

This material is based upon work funded by Zhejiang Provincial Natural Science Foundation of China under Grant No.LQ12E09002;Project(51308497)supported by National Natural Science Foundation of China.

\section{References}

[1]H. Zhang. Soil's Parameter Inversion and Analysis Based on Static Pressure Precast Concrete Pile's Static Loading Test, J. Electric Power Survey \& Design.2011 (2)19-22.

[2]C.d. Hong. Methods that Estimating the Side Frictions from the Portion to be Excavated in the Pile Axial Static Loading Tests, J. Soil Engineering and Foundation.2013 (3) 127-129.

[3]R.G. Liu, S.Q. Li, M.J. Li et al. Static test and finite element analysis of new kind of anchorage for CFRP tendon, J. Industrial Construction. 2011(41)624-627.

[4]Y.H. Wu. Application of Several Reaction Devices for Foundation Piles Static Load Test, J. Jiangxi Building Materials. 2011(1)60-61.

[5]G.L. Wang, Y.F. Yu. Construction of the Reaction Frame for Static Load Test, J. Jiangsu Science and Technology Information. 2011(5)46-47.

[6]S.H. Chen. Static Load Test and Finite Element Analysis of Major Diameter Pile. J. Gansu Water Resources and Hydropower Engineering. 2012, 48(3)33-34. 